\title{
Construct A Credit Evaluation Framework of E-commerce ${ }^{\mathbb{1}}$
}

\author{
Yin Shengbin ${ }^{1,}$, Zhang Hongyun ${ }^{2, b}$ \\ ${ }^{1}$ Hebei University ,Baoding, China, ${ }^{2}$ Baoding ICBC ,Baoding, China \\ aysb@hbu.cn, ${ }^{b}$ Zhanghy2004628@sina.com.cn
}

Keywords: Application e-commerce; credit evaluation; framework

\begin{abstract}
As an important commercial application, E-commerce is widely used with the development of Internet technology. However credit disks block the progress of E-commerce in the non-standard market environment, Analyzing credit management modes such as eBay and Taobao, this paper proposed a new credit calculation formula and construct a credit evaluation framework, in order to improve trading success rate, to avoid commercial fraud, and to contribut information construction of China.
\end{abstract}

\section{Introduction}

The market economy is a kind of credit commodity economic, credit is the foundation and Life Line of market economy, especially in the economic globalization process, and the credit is a permit to enter the international market. E-commerce as a commercial activity, credit is also the basis of the existence and development. Moreover, E-commerce with remote, recording can be modified, the complexity of the main characteristic, decided its credit issue is more outstanding. Credit problems already were the most important factor to restrict the healthy development of e-commerce. Both parties to the transaction information asymmetry, unsound legal system, immature credit evaluation system and technical means of support, as well as weak e-commerce credit consciousness, these are the main reason of e-commerce credit risk [1].

\section{E-commerce credit development}

\section{A. $\quad$ The credit}

The credit is a kind of business activities which provide the necessary goods, ensure their payment return and gain profit for fiduciary in the commodity exchange or other economic activities by accrediting party through contractual relationship of both sides [2]. The different research viewpoint on credit has different explanation. From the economics viewpoint credit is using borrowing money or deferred payment of goods trading activities; And from social science research the credit is a social evaluation of some person's (natural person or legal person ) obligations ability especially the solvency ability. Western countries from pure economic perspective consider credit to be sold on credit activity by hysteresis of exchange of value, and by agreement and contract guarantee under different time intervals.

B. The e-commerce credit

Perfecting credit management model is the basis of e-commerce transaction and the key of development [3]. Because e-commerce is virtual, there are still many problems in e-commerce credit. Customers have higher requirements of online suppliers supply capacity, morals and credibility [4]. E-commerce credit is deemed to be credit relationship of consisting of three parties, that are Vendee, Vendor and the e-commerce platform provider in e-commerce transaction. Ecommerce as a network products, rely on the network. In this shopping community the biggest characteristic of the buyer and the seller is information asymmetry. Therefore honesty and trustworthiness is the key to complete the transaction.

\section{C. $\quad$ Credit management models within China and abroad}

$\diamond \quad$ The United States e-commerce website: eBay.

\footnotetext{
(1) This research funded by the project of Baoding science and technology, its number is 12ZG007
} 
eBay using a third party certification credit model. The United States in order to ensure the safety and reliability of electronic transaction effective implementation, the third party online institutions are not less than 50 to run market operation out of the legal framework at present.One of the most effective organizations is online certification organization that prevents the vendee or vendor online fraud by the third party guarantee and supervision [5].

eBay credit evaluation system is mainly composed of three aspects:credit evaluation, the seller rating services and trade disputes. In each transaction completed, buyer and sellers can be given one of the evaluations: positive, negative and neutral by each other.Evaluation system helps us to reduce the probability of fraud.

Since 2007 May, eBay began to use the seller service grading system. Buyers carry out overall credit evaluation for sellers (positive comment,moderate comment or negative comment), through the following four aspects service the seller service are graded by buyers: 1) Differences between the goods description and entity; 2) Communication quality and speed of response; 3) rationality of goods delivery time; 4) Rationality of transport and handling fee. These four scores are called the seller services rating. The scores of seller services rating are generally between 1 and 5 points, 5 is the highest score, 1 is the lowest.In four ratings $1 \sim 2$ points means the buyer make negative evaluation, represent buyer dissatisfaction of the transaction. In order to make the buyer to get a better shopping experience, eBay will recommend some goods of sellers who get better score from seller service rating in last month to buyers. When the seller service score reach a certain fraction, the seller will be regarded as excellent seller, they will be acquired more display in searching, and reward of the top-rated seller, cost of concessions, moreover to help seller to improve product popularity, thereby sales promoting. Sellers getting low score from the seller services rating will be shielded. Therefore, for the sellers the seller service score has great significance.

$\diamond$ A well-known domestic e-commerce site: taobao

In taobao's basic shopping process, buyers browse the merchandise information, check the seller credit evaluation and product information, and then decide whether to buy, if the purchase of goods, need to validate users. The buyer pays the payment, the seller shipped, buyers receipt. Buyer received the goods after the seller of credit and commercial evaluation. As a seller, also need to register certification, received the buyer payment delivery, after the success of the transaction to buyers credit evaluation. The credit evaluation model can improve the success rate of the transaction, reduce transaction risk.

At present, taobao's credit model process is as follows: 1) Registration; 2) Credit rating.Taobao credit evaluation model is that buyers and sellers make evaluation each other after end transaction; 3) Consumer protection services. According to consumer protection services agreement and taobao other regulations, the user chose to participate in the consumer protection services and some aftersales services. These services include "Advance payment", "no reason to return in 7 days ", " one fake, and we will pay a triple refund ", " virtual goods lightning delivery" , "digital goods and home appliances repair in 30 days" and other specific services; 4) Online community, taobao to establish an online community, users of the network shopping experience experience exchange, can effectively supervise the fraud prevention, online community for other credit measures to perfect the role of complement.such as Fig.1 


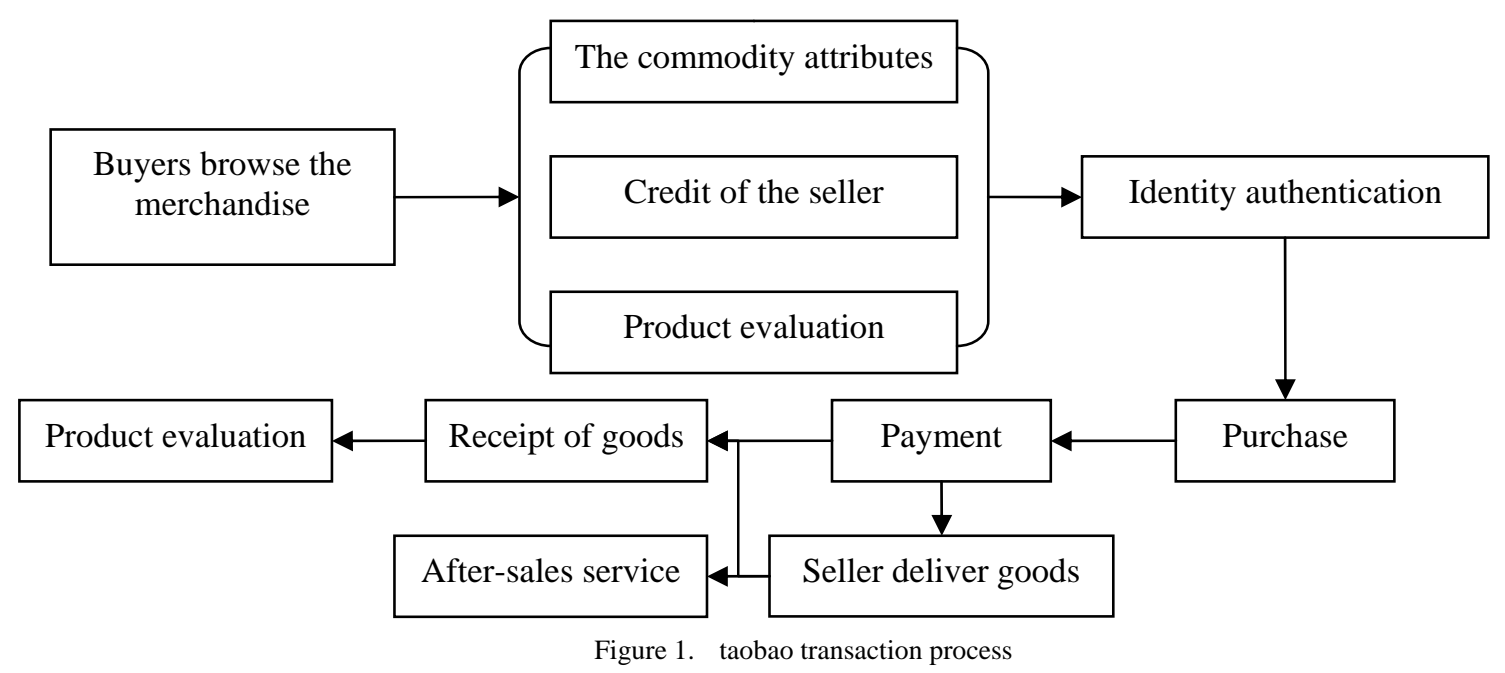

Based on the above two platform of e-commerce transaction process overview, it can be found that more successful trading platform guarantee the safety of the transaction through the third party certification, evaluation mechanism, identity authentication and other methods. However there are still some credit risks and vulnerabilities, these directly affect transaction to run smoothly. These credit risks have the following aspects: 1) Credit speculation; 2) Payment without delivery; 3) Description of goods does not conform to; 4) Failure to fulfill its promise of service; 5) Malicious evaluation; 6) Malicious retaliation. So we should construct a more perfect credit evaluation framework.

\section{Constructing perfect credit evaluation framework}

A. It can directly link personal transaction credi t to establish and improve the individual credit system.

Learn some western countries' experience, each person is assigned a lifelong effective social security ID, the ID cannot copy or forgery. At the same time, the credit for each person to make a credit report. In online trade, both parties can query other party's credit status from credit database. Once there is some infringement of credit in the transaction, not only is it recorded to the person's credit report, but it influence subsequent transaction.

Improve the individual credit calculation formula, which can better describe the individual's credit rating, helps to avoid transaction fraud. This paper presents a calculation method on individual credit to aggravate fraud credit punishment.

In the formula: $\mathrm{Ri}$ is expressed as No. i transaction weight(transactions in different scale and different content of transaction have different weights ); Pi is expressed as No. i transaction obtained fraction of evaluation ( there are many companies using 5 points system, also can use hundred mark system, in the formula should be uniformly hundred mark system); $\sigma_{i}$ is expressed as basic variance of the same transaction evaluation ( there is a bigger difference from some different individual evaluations, so we should calculate variance to deal with the same transaction evaluation, it can avoid some individual malicious behavior ), $\varphi_{m}$ is expressed as No. m credit fraud weights. So the person's credit calculation:

$$
\mathrm{C}_{\mathrm{id}}=\frac{1}{i} \sum_{i=1}^{n}\left(\sigma_{i}+P_{i}\right) R_{i}-\sum_{m=1}^{N} 2^{m} \varphi_{m}
$$

Such as table 1and Fig.2, there are a person's transaction digital and the credit calculation.

TABLE I. COMPARE OF THE TWO FRAMEWORKS

\begin{tabular}{|c|c|c|c|c|c|c|}
\hline \multirow{2}{*}{$\begin{array}{c}\text { Evaluation of } \\
\text { frequency }\end{array}$} & \multicolumn{6}{|c|}{ items } \\
\cline { 2 - 7 } & fraction & weight & variance & $\begin{array}{c}\text { fraud } \\
\text { weight }\end{array}$ & $\begin{array}{c}\text { Fraud } \\
\text { frequency }\end{array}$ & $\begin{array}{c}\text { the person's } \\
\text { credit }\end{array}$ \\
\hline 1 & 85 & 0.7 & 3.25 & 5 & & 61.76 \\
\hline
\end{tabular}




\begin{tabular}{|c|c|c|c|c|c|c|}
\hline \multirow{2}{*}{$\begin{array}{c}\text { Evaluation of } \\
\text { frequency }\end{array}$} & \multicolumn{7}{|c|}{ items } \\
\cline { 2 - 7 } & fraction & weight & variance & $\begin{array}{c}\text { fraud } \\
\text { weight }\end{array}$ & $\begin{array}{c}\text { Fraud } \\
\text { frequency }\end{array}$ & $\begin{array}{c}\text { the person's } \\
\text { credit }\end{array}$ \\
\hline 2 & 70 & 0.5 & 4.7 & 6.4 & & 49.56 \\
\hline 3 & 93 & 0.9 & 10.3 & 12.2 & & 47.51 \\
\hline 4 & 0 & 0.4 & 6.1 & 8 & 1 & 31.51 \\
\hline 5 & 90 & 0.75 & 3.5 & 5.6 & & 20.33 \\
\hline 6 & 100 & 0.95 & 20.5 & 30 & & 22.47 \\
\hline \multicolumn{7}{|l|}{} \\
\hline
\end{tabular}

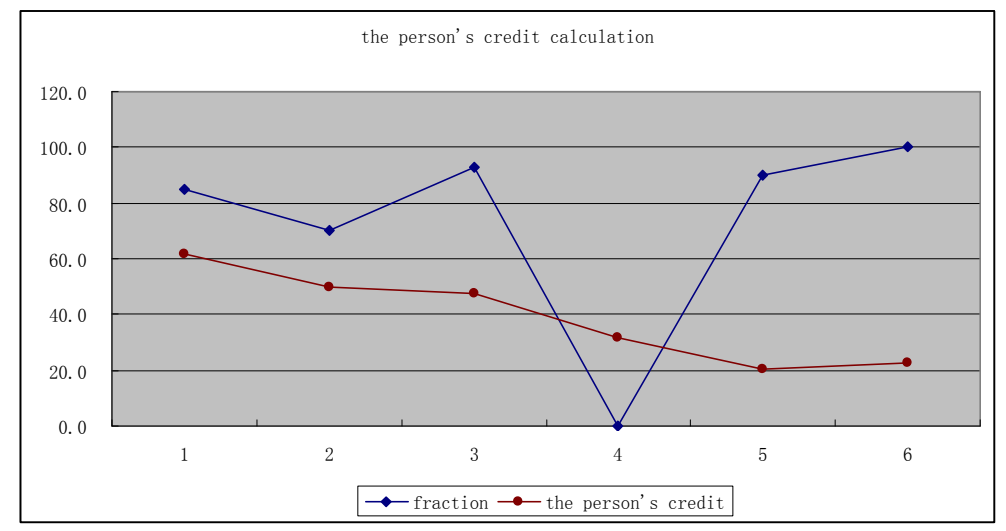

Figure 2. The person's credit calculation

\section{B. $\quad$ The standard transaction process}

During the transaction, both parties to the transaction to social security ID login, through reference library to get the credit, to determine whether the conduct transactions with. When transaction is normal completion, information of evaluation is stored in the credit database after summary calculation. Credit bank by the government departments to manage and control, and shall not be electronic business operation entity to master, in order to avoid illegal operation.such as Fig.3.

\section{Establish and improve the information security mechanism}

In these years, e-commerce develops rapidly, from the traditional B2B (business-to-business) or B2C (business-to-consumer) mode to P2P mode. In the P2P e-commerce systems, the transaction node is the buyer and the seller. According to Netguide 2008 China Internet survey report shows, P2P e-commerce has become a major online transactions, and forecasting the next few years, this pattern of earnings will grow considerably. Major domestic and foreign electronic Business Company (Taobao, eBay, Amazon) have opened their own P2P e-commerce platform, data is displayed in the P2P e-commerce platform on the volume is increasing rapidly. But, in this environment to build up trust management model is susceptible to common, oscillation, malicious attacks, resulting in credit evaluation error. Study of [6] based on trust cloud dynamic trust management model (TCDSTM). TCDSTM use of cloud theory to describe the trust and confidence level, and then has the ability against the attack of the global trust degree of fusion algorithm, the type of the node identification and topology reconfiguration mechanism. In order to resist collusion, oscillation, malicious attacks, improve the success rate of the transaction.

\section{Conclusion}

With the increase in number of Internet use in China, online shopping and payment by bank card using Internet consumption patterns have started to pop, also in fast-growing market share, endless stream of e-commerce website. It from system of views start, stressed people in system in the of Center status, will environment and people, and people and tools, and people and subject of labour organic to contact up, with system of target, and system of composition to defines e-commerce, so makes it has productivity of nature.The development of e-commerce needs the credit guarantee. 
Through establishing perfect credit guarantee mechanism, it can form an honest and credible business environment to effectively reduce transaction risk and promote the rapid development of ecommerce.

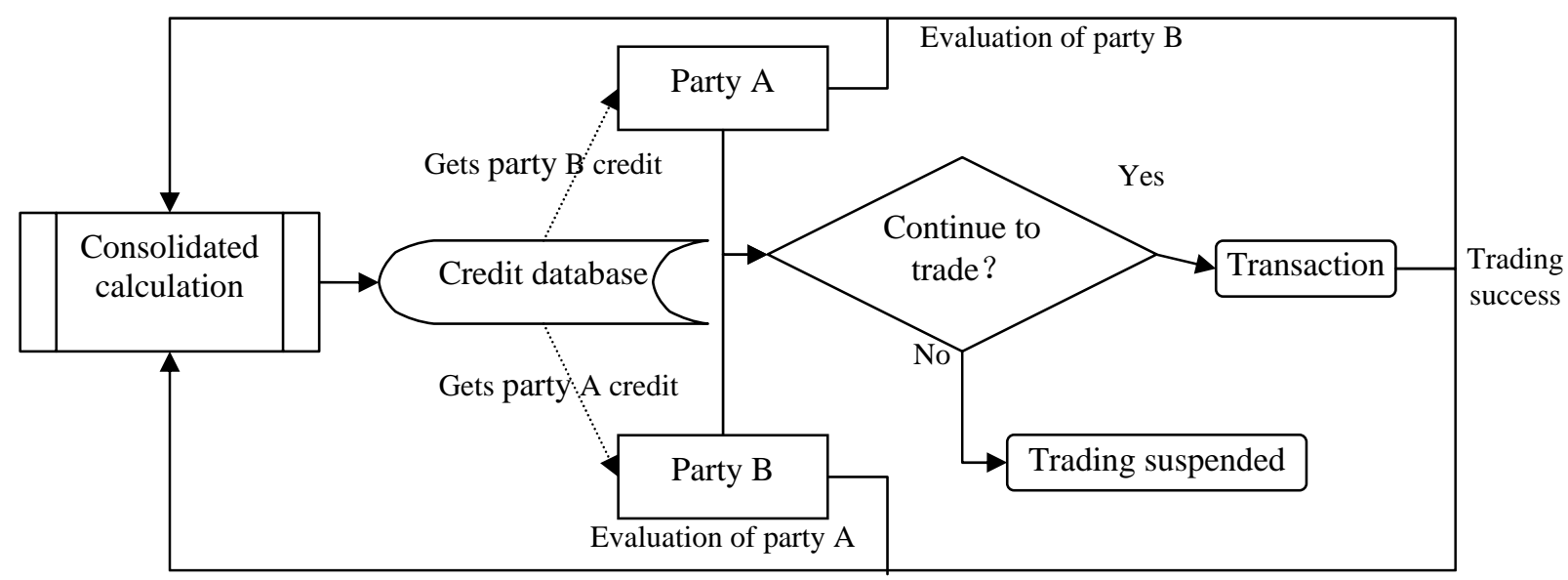

Figure 3. The standard transaction process

\section{References}

[1]. XuDapeng,WangChao. E-commerce creditrisk research,Operation Manager,2011, (20） : 13 .

[2]. ChenChun . E-commerce Creditability Research Based on B2BModel,Xidian University,2005,13-16.

[3]. Adriano Pereira,Arlei Silva,Wagner Meira Jr. ,Vigilio Almeida. Seller's Creditability in Electronic Markets:A Complex Network based Approach. WICOW’ 09,2009: 59.

[4]. FahriUnsal,Kurt Komaromi,Scot Erickson . Trust in E-commerce:Social Networks. Institutional Credibility. International Journal of E-Adoption,2011,3(4): 1-12.

[5]. LiXiang. The credit Control Model of C2Ce-Business Credit Transaction,Jilin Universit M. Young, The Technical Writer’s Handbook. Mill Valley, CA: University Science, 1989.

[6]. LI Zhi-yuan, WANG Ru-chuan. Dynamic secure trust management model for P2P e-commerce environments, Journal on Communications,2011,3:50-58. 